\title{
The Construction of Orbit for CRTS I Type Plate Without a Frantic
}

\author{
Jumble \\ Hong Gan ${ }^{1, a}$, Yizhen Yang ${ }^{2, b}$ \\ ${ }^{1}$ The President's office, Anhui Polytechnic University, \\ 8 Beijing Road in Wuhu, China 241000 \\ ${ }^{2}$ College of Civil Engineering and Architecture, Anhui Polytechnic University, \\ 8 Beijing Road in Wuhu, China 241000 \\ agh@ahpu.edu.cn, byyiz2006@163.com
}

Keywords: CRTS I type without a frantic jumble of orbit, Construction technique Coarse aggregate, Mass control

Abstract. Taking the railway track construction practice of ningan intercity railway as an example. Emphatically discusses the CRTS I type without a frantic jumble rail construction technical preparation, base plate, rail board shop coarse and fine adjustment, cement emulsified asphalt mortar filling layer perfusion and other key working procedure of the construction technology and construction technology. Summarizes the basic blending ratio of cement emulsified asphalt mortar, the process flow of cement emulsified asphalt mortar filling, the control means of key technology and quality control, and the method of quality testing. Hope to provide reference for similar project construction.

\section{Introduction}

Project introduction. The ning'an intercity railway is an extension of the inter-city passenger railway network in the Yangtze river delta. It is located in jiangsu province and anhui province, and is located in the south of the Yangtze river and is basically parallel to the Yangtze river. East of jiangsu province nanjing, through the anhui province of maanshan, wuhu, tongling, chizhou city and other Yangtze river areas along the Yangtze river, cross the Yangtze river, west to anqing city, the total length of $257.480 \mathrm{~km}$. Ning an inter-city railway design speed of $250 \mathrm{~km} / \mathrm{h}$, adopting CRTS I type plate without a frantic jumble orbit.

\section{Technical preparation for construction}

Subgrade section of CP III layout. CP III sign should be set in the stable, reliable, and is not easy to damage and easy to measure, should be taken to prevent frostbite, settlement and prevention against mobile protective measures. Subgrade section based on CP III marks shall be buried in the catenary, and based on catenary great mileage on one side of the side lines. CP based whole casting III foundation and catenary, the upper outside using $\Phi 20$ CMPVC tube for die casting of reinforced concrete columns, CP III sign buried on the post, and ensure the above design rail surface $30 \mathrm{~cm}$ (in fig 1). 


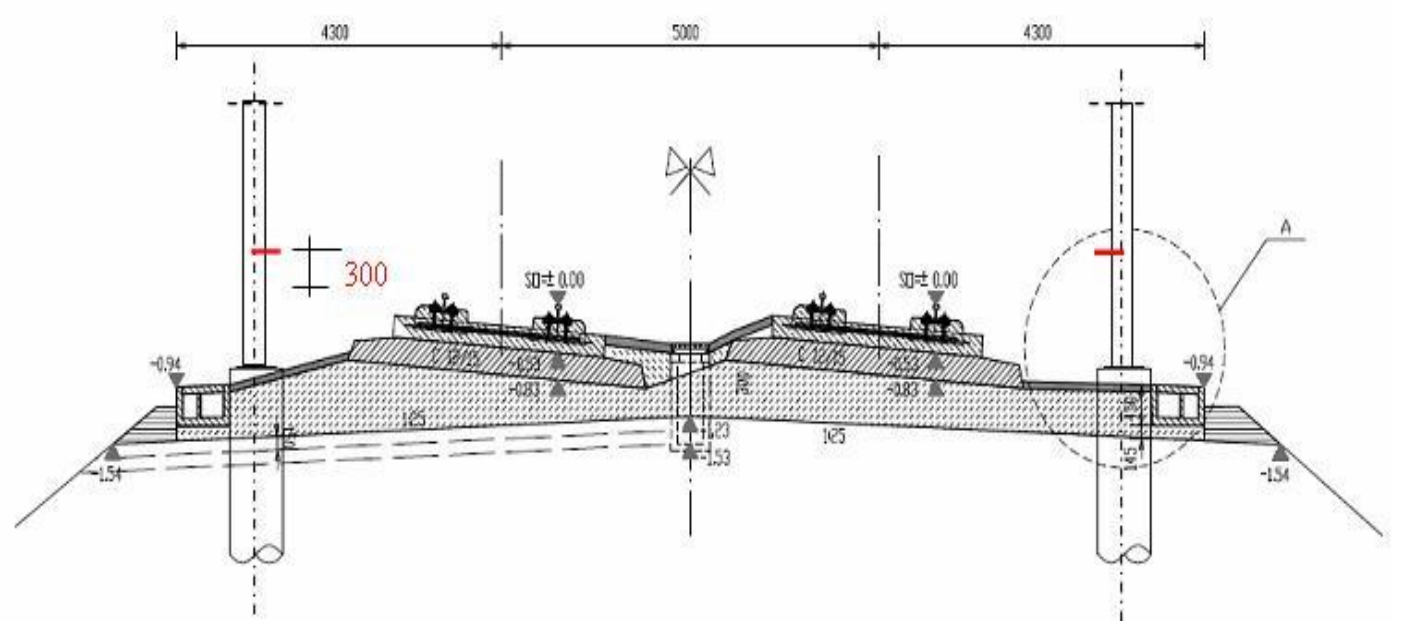

Fig. 1 subgrade section of CP III setting map

Subgrade section of CP III longitudinal $50 \sim 70 \mathrm{~m}$ setting a pair, note with catenary anchor falling under the effort of compensation and the power switch operation cases of conflict., It can be set in the line small range end when the conflict.

Offline acceptance. Before the construction of the tracks, the offline engineering must be fully inspected from the following three aspects.

CP III control network measurement evaluation. CP III control network measurement should meet the requirements in the offline engineering settlement and deformation, and through the settlement after the assessment.

The high - level measurement, flatness and width of beam seam are accepted. According to the width of the actual beam, the special design of the slab board is carried out.

Design of track board fabric. The design of the CRTS I board without the track sheet is to determine the exact position of the convex platform. Only the position of the convex block can be determined. According to the design requirements, the design of CRTS I - type trackless rails must meet the following criteria: When the convex retaining platform is located, it should be combined with the layout of the track board, the actual length of the bridge and the positioning of the convex platform to ensure that the thickness of the resin around the convex block is $30 \mathrm{~mm} \sim 50 \mathrm{~mm}$; When the seam of the beam is greater than $110 \mathrm{~mm}$, the construction of the base plate of the beam end shall be designed in accordance with the suspension of $0 \sim 40 \mathrm{~mm}$, ensuring that the space of the adjacent rail of the girder joint shall be no more than $650 \mathrm{~mm}$; When the actual width of the beam joint is less than $70 \mathrm{~mm}$, the base end of the seam of the girder joint must be contracted properly to ensure the installation of the expansion joint.

According to the above design requirements, the limit value of the width of the girder seam is calculated by the width of the beam of 24-meter beam and 32-meter beam: 650-268.5 x 2=113 $(\mathrm{mm})$. The 32-meter beam is $650-260.5 \times 2=129(\mathrm{~mm})$. However, in order to ensure that the spacing between the joints of the beam joints is not greater than $650 \mathrm{~mm}$ and the calculation is uniform, the design specifies that the value of the reserved value of the beam joints shall be uniformly applied to the limit of the cloth plate by not greater than $110 \mathrm{~mm}$.

Construction of cement emulsified asphalt mortar material storage. Cement emulsified asphalt mortar raw material is very sensitive to the environment, according to the engineering management center of the plate without a frantic jumble orbit cement emulsified asphalt mortar construction material storage management method ", according to each face perfusion orbit 60 boards every day, need asphalt $18 \mathrm{t}, 35 \mathrm{t}$, dry powder material added four days time, maximum storage capacity of 72 tons of asphalt construction schedule arrangement, in mixing station mixing station 1 and 2, make 
full use of the mixing station bin canopy, respectively equipped with two DZJ50 emulsified asphalt storage tanks, the largest storage capacity of $80 \mathrm{t}$, construction of dry powder material library respectively each one (repository area $252 \mathrm{~m} 2$, is the largest reserves of $60 \mathrm{t}$ ), and configure the 12 sets of $1.5 \mathrm{P}$ air conditioning, used to store temperature control. The above configuration meets the requirements of two working faces at the same time.

\section{CRTS I type slab without a frantic jumble track process construction technology}

Base plate construction. CRTS I type plate without a frantic jumble orbit curve are set up on the base board, the outer rail way up, and complete the transition in the easement curve segment linear transformation. The width of the base plate of the bridge location is $2.8 \mathrm{~m}$, the base is divided by the fabric design in the beam, and the center position of the corresponding convex center is set at $20 \mathrm{~mm}$ expansion joint. The beam surface of the base area is not waterproof and protective layer. The beam surface of the line $2.6 \mathrm{~m}$ in the rail line is pulled and treated during the prefabrication of the beam field. The beam body is connected with the base by the embedded sleeve.

The base plate width of the roadbed section is $3.0 \mathrm{~m}$, and the base length of the base bed is set, and the base length corresponding to the length of the length of each 3-4 block of the rail plate is set, and the center position of the convex center is set at a width of $20 \mathrm{~mm}$ expansion joint

Track board coarse and fine tuning. At the top of the convex block, the cross - ink line is drawn accurately. The vertical ink line indicates the center line of the track. The horizontal ink line is perpendicular to the direction of the track, and is in accordance with the interval requirement of the position of the track plate. After the track board is hoisted and transported to the paving position, the constructors hold the track plate slowly down and put on the support pad. Use a special crowbar to adjust the position of the track plate; The position and height of the track plate are precisely adjusted according to the base of the protruding platform. Steel ruler is used to measure the longitudinal distance between the adjacent convex block to ensure that the distance between the rail plate and the two convex blocks is the same and not less than $30 \mathrm{~mm}$. Using three Angle gauge, through the convex block on the stage of benchmark to adjust the direction of the rail plate (curve section to adjust Angle of each track plate, measuring method of checking and string), through the convex block on the benchmark, adjust track kits four points. The position of the measuring position is suitable for the rail plate support bolt hole and is located on the rail center line. Adjust according to the above steps until you meet the requirements. After the monolithic board has been adjusted, the adjacent plate height difference is adopted to meet the acceptance standard. When the state of the rail plate is accurate, the track plate is fixed in the gap between the rail plate and the convex retaining platform. In the meantime, the L type pressure device is fixed, the l-type pressure device is used to press the screw, and the screw sleeve is laid in front of the concrete casting of the base plate.

Cementing asphalt mortar filling layer. Cement emulsified asphalt mortar filling layer as the track plate and cushion layer between the concrete base, mainly on filling, support, bearing and force transmission effect, and can provide proper rigidity and tenacity to orbit. The performance of mortar has a direct impact on the durability of the track, which is one of the key points in the construction of the unrolling stone.

Technical indicators of quality of mortar filling layer (in table 1). 
Table 1 technical indexes of cement emulsified asphalt mortar filling layer

\begin{tabular}{|c|c|c|c|c|}
\hline number & projects & $\begin{array}{l}\text { Technical } \\
\text { indicators }\end{array}$ & & remark \\
\hline 1 & thickness & $40 \mathrm{~mm} \sim 60 \mathrm{~mm}$ & & - \\
\hline 2 & $\begin{array}{c}\text { Plate edge mortar } \\
\text { protruding }\end{array}$ & $\pm 10 \mathrm{~mm}$ & & - \\
\hline 3 & $\begin{array}{l}\text { The slurry of the } \\
\text { slurry is prominent }\end{array}$ & $-10 /+50$ & \multirow{2}{*}{\multicolumn{2}{|c|}{$\begin{array}{l}\text { Insert the amount } \\
\text { with } 0.6 \mathrm{~mm}\end{array}$}} \\
\hline 4 & $\begin{array}{c}\text { Interspace between } \\
\text { the filling and rail } \\
\text { plates }\end{array}$ & $\leq 50 \mathrm{~mm}$ & & \\
\hline \multicolumn{5}{|c|}{ New cement emulsified asphalt mortar index (in table 2 ). } \\
\hline $\begin{array}{c}\text { test } \\
\text { projects }\end{array}$ & $\begin{array}{c}\text { Slurry } \\
\text { temperature } \\
\left({ }^{\circ} \mathrm{C}\right) \\
\end{array}$ & $\begin{array}{l}\text { Pan pulp } \\
\text { rate }(\%)\end{array}$ & $\begin{array}{c}\text { Air } \\
\text { content } \\
(\%) \\
\end{array}$ & $\begin{array}{c}\text { The apparent } \\
\text { density } \\
\left(\mathrm{kg} / \mathrm{m}^{3}\right)\end{array}$ \\
\hline index & $18 \sim 26$ & 0 & $8 \sim 12$ & $>1300$ \\
\hline
\end{tabular}

\section{The quality factor analysis and control measures of cement emulsified asphalt mortar influence the filling layer quality factor}

The main indexes of the quality control of cement emulsified asphalt slurry filling layer are filled with full measure, homogeneity of section and surface compactness. The construction quality of cement emulsified asphalt mortar filling layer is closely related to mortar property and construction process.

Control of the homogeneity of the filling layer section. The homogeneity of section is an important index to ensure the overall mechanics and deformation of the filling layer. For with the new section homogeneity of mortar for the degree of separation and homogeneity, and the new mortar separating degree unqualified (passenger dedicated line CRTS I type plate without a frantic jumble orbit cement emulsified asphalt mortar interim technical conditions for separation degree should be less than or equal to $1 \%$ ), can lead to dry powder material in sand sinking, bubbles rise, thus mortar performance distribution in vertical direction. The homogeneity of the new mixed mortar is mainly due to the disqualification or uneven mixing of raw materials.

\section{Conclusion}

CRTS I type plate without a frantic jumble orbit is a new type of track structure, which is developing rapidly in recent years, for the high-speed railway "fast, stable and comfortable" laid a solid foundation, but bag injection method is used to the construction of cement emulsified asphalt mortar, construction technology is more complicated. Cement emulsified asphalt mortar is very sensitive to the environment, the oil pollution, high temperature (over 35 degrees) and low temperature (below 5 degrees) and rainy day construction, are easy to cause the mortar appear bubbles, fold, the common quality problems such as warping. The cement emulsified asphalt mortar matching equipment must be fixed, reasonable construction organization and the on-site logistics 
scheme. Through the construction method of "boilerplate lead, summary analysis, full line spread", ningan railway has mastered the construction process of each process, laying the foundation for the smoothness and comfort of high-speed railway.

\section{Acknowledgements}

This work was financially supported by the Wuhu Key Project (2013cxy08). Anhui province natural science fund projects(1708085QE121). Anhui province higher education promotion project(TSKJ2016B25).

\section{References}

[1] Gan hong, Yang yizhen. Nonlinear dynamic analysis of the damping frame structure system. Advanced Materials Research, in 2012 the civil, structural and environmental engineering international academic conferences.

[2] Gan hong, Yang yizhen. Application research on base isolation building structure [J]. Journal of Anhui Polytechnical University: Natural science edition,2011,26(1):1-4.

[3] Gan hong,Gao fei. The dynamic responses of the structure of the isolation system [J].Hefei: Journal of hefei university of technology,2004,7

[4]Lu chunfang. Standardized management of railway construction projects[M]. China Railway Publishing House, 2013.3. 